(2) Open Access Full Text Article

\title{
Acyclovir and hydrocortisone cream for the early treatment of recurrent cold sores
}

\author{
This article was published in the following Dove Press journal: \\ Virus Adaptation and Treatment \\ II January 20 I I \\ Number of times this article has been viewed
}

\author{
Carrie A Sailer' \\ Spotswood L Spruance ${ }^{2}$ \\ Christopher M Hull' \\ 'Department of Dermatology, \\ ${ }^{2}$ Department of Medicine, Division \\ of Infectious Diseases, University of \\ Utah, Salt Lake City, USA
}

Correspondence: Christopher M Hull Department of Dermatology, 4A330 School of Medicine, University of Utah, 30 North 1900 East, Salt Lake City, Utah 84I32-2409, USA

Email christopher.hull@hsc.utah.edu

\begin{abstract}
Current antiviral therapies for herpes simplex labialis primarily reduce healing time. Since the host immune response also plays a role in both controlling recurrent infection as well as producing clinical symptoms, new studies are showing efficacy using topical corticosteroids. This review will evaluate the safety and efficacy of 5\% acyclovir-1\% hydrocortisone cream (Xerese $^{\mathrm{TM}}[\mathrm{US}], \mathrm{Xerclear}^{\mathbb{R}}[$ Europe]) for treatment of patients with herpes simplex labialis. A large, randomized, double-blind, placebo-controlled study recently demonstrated that treatment with $5 \%$ acyclovir- $1 \%$ hydrocortisone cream significantly decreased the percentage of ulcerative lesions, reduced lesion healing time, and decreased mean lesion area compared with both topical acyclovir alone and vehicle.
\end{abstract}

Keywords: herpes labialis, herpes simplex virus, HSV, acyclovir, hydrocortisone, ME-609, Xerese, Xerclear

\section{Introduction}

Herpes simplex viruses (HSV) are common and ubiquitous viral pathogens that cause skin infections and are seen in a worldwide distribution. Two strains of herpes simplex viruses have been identified, including HSV-1 and HSV-2. The most common clinical presentation of HSV-1 infection is herpes labialis, commonly known as cold sores or fever blisters. Herpes simplex labialis (HSL) occurs in $20 \%$ to $40 \%$ of the general population and manifests as recurrent vesicular herpetic lesions on the lips or around the mouth. ${ }^{1-7}$ Inoculation of this virus into susceptible mucosal surfaces occurs via close personal contact. Serologic studies show that approximately $60 \%$ of the adult population in the United States is infected with HSV-1, although many infected persons are asymptomatic. ${ }^{8}$ Symptomatic infections can be marked by significant morbidity and recurrence. Primary herpes simplex infections are accompanied by systemic signs, longer duration of symptoms, and higher rate of complications, whereas recurrent episodes are often milder and shorter. The frequency of recurrent infections is variable, ranging from rare episodes every few years, to monthly or more frequent outbreaks among a smaller proportion of individuals. The severity is most often mild with lesions lasting approximately 1 to 2 weeks, although uncomfortable and cosmetically disfiguring. Among those with an underlying immunosuppressive disease, however, lesions are of longer duration and may spread to cause major morbidity.

\section{Current antiviral therapies}

In recent years, the scientific understanding of HSV infections has grown and with it has come the development of safer and more effective antiviral therapies. The introduction 
of nucleoside analogs (acyclovir and others) greatly improved the treatment of HSV-related illnesses. These medications decrease herpes viral replication by inhibition of viral DNA polymerase and either termination of DNA chain extension or self-incorporation into viral DNA. ${ }^{9,10}$ Nucleoside analogs are available commercially for the treatment of herpetic keratitis, herpes zoster, herpes genitalis, mucocutaneous herpes simplex in immunosuppressed hosts, neonatal herpes, and herpes encephalitis. Acyclovir is the prototype drug for HSL and acts as a nucleoside analog to competitively inhibit herpes viral DNA polymerase. It is phosphorylated initially by a herpes virus thymidine kinase, and subsequently by host cell enzymes to form a nucleoside triphosphate. ${ }^{11}$ The active drug then competes for binding to the viral DNA polymerase in virally infected cells. This mechanism reduces viral replication in a dose-dependent manner, but does not impact cell death. Acyclovir is highly selective for virally infected cells because of its high affinity for the viral thymidine kinase enzyme and its low affinity for cellular thymidine kinase. Acyclovir is commercially available in topical, oral, and intravenous formulations.

Valacyclovir is a prodrug that is enzymatically converted to the active drug, acyclovir. Therefore, valacyclovir has the same mechanism of action and a similar safety profile as acyclovir. Valacyclovir, unlike acyclovir, has a high oral bioavailability which allows for less frequent dosing and potentially higher drug levels. ${ }^{12}$ Penciclovir, structurally similar to acyclovir, inhibits HSV viral DNA synthesis and replication and is approved for the treatment of herpes labialis as a cream. Famciclovir is a well-absorbed oral prodrug of penciclovir, which is completely converted to penciclovir after absorption. Famciclovir has high oral bioavailablity similar to that of valacyclovir.

The current standard of care for recurrent herpes labialis involves an oral or topical antiviral given episodically at the onset of each recurrence. Oral agents may be given as prophylaxis in the absence of lesions to prevent recurrences. ${ }^{9,10,13}$ A variety of topical over-the-counter preparations are also available, but in most cases the mechanism of action is ambiguous and very few clinical trials have been performed to define their efficacy. Docosanol 10\% cream (Abreva; GlaxoSmithKline) is the most well-studied, over-the-counter product, with 2 randomized trials suggesting some efficacy of treatment. ${ }^{14}$ Because an unrelated placebo was used in these studies, the true level of efficacy cannot be objectively determined.

Demonstrating clinical efficacy of topical antiviral drugs among immunocompetent patients has been difficult, probably due to drug bioavailability problems, the small amount of efficacy, and the need to start treatment very early in the course of the disease. Studies of acyclovir ointment have provided little evidence of efficacy for herpes labialis in immunocompetent subjects, ${ }^{15-18}$ but have shown efficacy in immunocompromised patients. ${ }^{19}$ Acyclovir was shown to penetrate skin more effectively from a cream-based formulation than from an ointment, and acyclovir cream is an approved treatment for cold sores in immunocompetent patients. ${ }^{20}$ Penciclovir cream improves lesion healing and can be used for treatment of herpes labialis. ${ }^{21,22}$

Due to the limited efficacy of topical treatments and the inconvenience of frequent dosing regimens, oral antiviral medications are frequently preferred for treatment of herpes labialis. Oral acyclovir, valacyclovir, and famciclovir are all currently approved for clinical use. Small studies have suggested that oral acyclovir reduces healing time 1 to 2 days compared with placebo, but has no effect on aborting lesions (aborted lesions are those episodes which do not progress beyond the papule stage). ${ }^{13,23,24}$ Similarly, larger clinical studies involving famciclovir have shown a reduction in healing time without prevention of ulcerative lesions. ${ }^{25-27}$ Oral valacyclovir has been shown in studies to reduce healing time and suggested a trend toward an increase in the frequency of aborted lesions. ${ }^{13,28}$ These data, combined with the fact that only 1 or 2 doses of the oral prodrugs are needed, have led to recommendations for high-dose, short-course therapy with oral valacyclovir and famciclovir as primary therapies for herpes labialis.

\section{Limitations of current therapies}

The clinical course of herpes labialis consists of lesion development, which is primarily driven by virus-mediated cell lysis, and the secondary immune response to virus reactivation. Once the immune response successfully clears the virus, cells re-epithelialize closing the defect. The development of lesions has been shown to occur rapidly, with maximum lesion severity achieved within 8 hours after the onset of the papular stage. ${ }^{29}$ Since the lesion development phase is so brief, antiviral therapies are unlikely to significantly affect maximum lesion severity. In fact, multiple clinical studies have failed to show improvement in the frequency of aborted lesions or the maximum lesion size with antiviral therapy. ${ }^{29}$ The longest phase in the clinical course of herpes labialis is lesion resolution. This phase is analogous to healing of a small traumatic wound, and may take up to 10 days to resolve. Wound healing in herpes labialis is a more complex process than seen in trauma, due to the virally 
infected keratinocytes and secondary immune response. This phase may be accelerated using antiviral therapy due to reduction in viral replication. In fact, the primary clinical benefit observed with antivirals has been reduction in lesion healing time..$^{13,29,30}$

Despite many advances in antiviral therapies, a highly efficacious treatment for recurrent herpes labialis in immunocompetent patients remains somewhat elusive. Both the clinical course of herpes labialis and the targets of current therapies impose limitations on the success of treating recurrent episodes.

The secondary immune response plays a central role in faster and more effective resolution of recurrent infections, but it is probably responsible for many of the clinical symptoms associated with recurrent herpes labialis. These symptoms can persist for up to a week after the virus can no longer be isolated. ${ }^{31,32}$ Since current antiviral therapies for herpes labialis have no impact on host immune function or the inflammatory cascade, and immune modulation could provide added clinical benefit, the use of topical corticosteroids has been explored in clinical studies.

\section{Corticosteroids}

Corticosteroids are known for their anti-inflammatory and immunosuppressive effects. They act primarily by binding and activating the glucocorticoid receptor, which up-regulates expression of anti-inflammatory cytokines and represses expression of many pro-inflammatory cytokines. Corticosteroids have been used as adjunctive therapy for a number of infectious diseases including bacterial meningitis, Pneumocystis carinii pneumonia, and cutaneous fungal infections with clinical improvement. ${ }^{33-35}$ They also display modest benefit when used concurrently with antivirals for treatment of herpes zoster. ${ }^{36}$ Significantly, corticosteroids have become the current standard of care for herpetic stromal keratitis. ${ }^{37,38} \mathrm{To}$ evaluate the use of corticosteroids for use in herpes labialis, Awan et al developed an animal model of recurrent HSV in mice using zosteriform HSV infection in the presence of adoptive transfer of immunity. Using this murine model, they demonstrated that topical treatment with ME-609, containing $5 \%$ acyclovir and $1 \%$ hydrocortisone, was significantly more efficacious than $5 \%$ Zovirax $^{\circledR}$ cream (GlaxoSmithKline), $1 \%$ hydrocortisone, or no treatment. ${ }^{39,40}$

\section{Proof-of-concept study}

To evaluate the safety and efficacy of topical corticosteroids on recurrent herpes labialis in humans, 3 previous exploratory studies have been conducted..$^{32,41,42}$ The first study was a proof-of-concept pilot study comparing the combination treatment of famciclovir and topical fluocinonide, a corticosteroid gel, to famciclovir alone on ultraviolet radiation (UVR)-induced herpetic recurrences. ${ }^{32}$ This study, conducted in 49 healthy volunteers, revealed a marked and significant reduction in the maximum lesion area in the combination therapy group $\left(48 \mathrm{~mm}^{2}\right)$ compared with the famciclovir alone group $\left(162 \mathrm{~mm}^{2}\right)$. It also revealed a decreased number of patients with lesion pain from $100 \%$ in the famciclovir alone group compared with 59\% in the combination therapy group. Furthermore, a trend in the combination group towards more aborted lesions ( $41 \%$ vs $8 \%$ ) was observed. ${ }^{32}$ Lesion healing time was also faster in patients receiving the combination compared with famciclovir alone (5.3 days vs 8.9 days). No increase in adverse events could be attributed to the use of corticosteroids in this study. Although corticosteroids have the potential to increase the magnitude and duration of viral shedding from the lesion, this process was not observed. The authors suggest that the use of the antiviral medication may have prevented this process from occurring. Overall, the study suggested that combining corticosteroids with antiviral agents was both efficacious and safe, and provided a precedent for continued evaluation of this therapeutic modality.

\section{Initial evaluation of 5\% acyclovir-I\% hydrocortisone cream}

A second study conducted in 2002 by Evans et al evaluated treatment with $5 \%$ acyclovir- $1 \%$ hydrocortisone cream, in a UVR model. This study demonstrated a reduction in the incidence of delayed classical lesions by $29 \%$ with $5 \%$ acyclovir-1\% hydrocortisone cream compared with placebo. ${ }^{41}$ Furthermore, healing time was reduced from 10.1 days to 9.0 days in patients receiving $5 \%$ acyclovir- $1 \%$ hydrocortisone cream compared with placebo, and median maximal lesion area was also reduced by $28 \%$ in the group receiving $5 \%$ acyclovir $-1 \%$ hydrocortisone cream. Lesion tenderness was noted in 42 patients treated with $5 \%$ acyclovir- $1 \%$ hydrocortisone cream, whereas 65 patients in the control group who developed delayed classical lesions experienced tenderness. These findings suggested that the combination of an antiviral and an immunomodulatory cream may reduce the severity of experimental UVR-induced herpes labialis. ${ }^{41}$ Similar to the Spruance et al study evaluating the use of famciclovir with topical fluocinonide, ${ }^{32}$ this study showed that combination therapy involving a topical corticosteroid reduced the severity, healing time, lesion size, and lesion tenderness compared with placebo or an antiviral alone. 


\section{Valacyclovir and topical clobetasol gel pilot trial}

A more recent study evaluated the safety and efficacy of patient-initiated therapy with oral valacyclovir and topical clobetasol gel $0.05 \%$ compared with an oral and topical placebo for recurrent herpes simplex labialis. ${ }^{42}$ Patients were randomized in a 1:1 ratio to receive either $2 \mathrm{~g}$ oral valacyclovir twice daily for 1 day and topical clobetasol gel $0.05 \%$ twice daily for 3 days, or matching oral and topical placebos. Patients were asked to initiate therapy within 1 hour of the onset of prodromal symptoms. This study demonstrated a marked reduction in the maximum lesion size from $54 \mathrm{~mm}^{2}$ in the placebo group to $9.7 \mathrm{~mm}^{2}$ in the valacyclovir-clobetasoltreated group. It also revealed a significant increase in the number of aborted lesions from $15.8 \%$ in the placebo group to $50 \%$ in the treated group. Furthermore, the time to healing was improved from 9.3 days to 5.8 days in the valacyclovirclobetasol arm. A significant reduction in the mean maximum area-under-the curve of lesion was reduced from $193 \mathrm{~mm}^{2}$ to $23 \mathrm{~mm}^{2}$. No serious adverse events were seen in either arm. ${ }^{42}$ The results of this small pilot study both confirmed and extended the data observed in the previous studies.

\section{Large-scale clinical trial of $5 \%$ acyclovir-I\% hydrocortisone cream}

The most recent study to evaluate the use of a combined treatment with acyclovir and hydrocortisone was a randomized, double-blind, patient-initiated, placebo-controlled clinical trial conducted in 2437 healthy subjects with a previous history of herpes labialis. ${ }^{43}$ Patients were enrolled from 51 sites in the United States and 4 sites in Canada, and were randomized in a ratio of $2.85: 2.85: 1$ of $5 \%$ acyclovir $-1 \%$ hydrocortisone cream, acyclovir cream alone, or placebo (vehicle). Of the subjects who met study criteria, 1443 initiated treatment during the study period. This study revealed a statistically significant higher percentage of nonulcerative recurrences (aborted lesions) in the 5\% acyclovir- $1 \%$ hydrocortisone cream group (42\%) compared with either acyclovir $(35 \%)$ or vehicle groups (26\%) (Table 1). The duration of the ulcerative lesions to loss-of-hard-crust was also significantly shorter in $5 \%$ acyclovir- $1 \%$ hydrocortisone cream group compared with vehicle (5.7 days vs 6.5 days), but was similar in the acyclovir-treated group (5.9 days) (Table 1). Similarly, the study showed a 1.5 -day reduction in time to lesion healing to normal skin in the $5 \%$ acyclovir- $1 \%$ hydrocortisone cream treated subjects compared with vehicle. The study revealed that the mean maximum lesion area of ulcerative lesions was comparable in the 5\% acyclovir- $1 \%$ hydrocortisone cream group $\left(41 \mathrm{~mm}^{2}\right)$ and the acyclovir group $\left(42 \mathrm{~mm}^{2}\right)$, but was smaller than the group treated with vehicle $\left(50 \mathrm{~mm}^{2}\right)$. The cumulative lesion area, however, was significantly reduced from $155 \mathrm{~mm}^{2}$ in the placebo group to $105 \mathrm{~mm}^{2}$ in the acyclovir group and $78 \mathrm{~mm}^{2}$ in the $5 \%$ acyclovir-1\% hydrocortisone cream group (Table 1). No serious adverse events related to the study medications were observed. This was the first large-scale clinical study to successfully demonstrate that $5 \%$ acyclovir- $1 \%$ hydrocortisone cream, a therapy combining an antiviral with a corticosteroid, prevents ulcerative lesions and results in more rapid healing time. No evidence of acyclovir resistance was noted in any of the subjects enrolled in this study.

\section{Adverse events}

Topical corticosteroids are well-known to cause cutaneous side effects such as atrophy, telangiectasia, and ulceration. ${ }^{44}$ Furthermore, they have the potential to exacerbate conditions such as acne, rosacea, and perioral dermatitis. In all studies examining the effects of combination therapy with topical corticosteroids, the study medications were well-tolerated with adverse events similar to placebo. Since all of these studies were conducted for a short duration, longitudinal studies should be conducted in the future to assess if repeated topical application of corticosteroids will lead to development of more significant side effects.

\section{Conclusion}

Previous studies have demonstrated a clear benefit using corticosteroids for treatment of herpes labialis. In fact,

Table I Patient responses to 5\% acyclovir-1\% hydrocortisone cream compared with acyclovir alone or placebo

\begin{tabular}{lllll}
\hline & $\begin{array}{l}\text { Aborted } \\
\text { lesions }\end{array}$ & $\begin{array}{l}\text { Lesion } \\
\text { healing time } \\
(\mathbf{d a y s})\end{array}$ & $\begin{array}{l}\text { Maximum } \\
\text { lesion area } \\
\left(\mathbf{m m}^{2}\right)\end{array}$ & $\begin{array}{l}\text { Cumulative } \\
\text { lesion area } \\
\left(\mathbf{m m}^{2}\right)\end{array}$ \\
\hline $5 \%$ acyclovir-1\% hydrocortisone cream & $42 \%$ & 5.7 & 41 & 78 \\
Acyclovir & $35 \%$ & 5.9 & 42 & 105 \\
Placebo & $26 \%$ & 6.5 & 50 & 155 \\
\hline
\end{tabular}

Note: Lesion healing time reflects the mean duration of the ulcerative lesions to loss-of-hard-crust. 
3 previous clinical studies have shown reduced lesion size and increased number of aborted lesions. In all studies, the combined therapy with an antiviral and corticosteroid was well tolerated with no significant adverse events and no suggestion of development of drug resistance. Clinical studies of antiviral treatment alone have shown only more rapid rates of healing. Combining antiviral therapies with corticosteroids provides the added benefit of increasing the number of aborted lesions, thus demonstrating enhanced clinical activity with combination therapy. The studies evaluating the use of corticosteroids for treatment of recurrent herpes labialis all supported the concept that corticosteroids were a valuable new tool in treating herpes labialis, and suggested that larger studies should be conducted to expand and confirm these findings. One such large, randomized, double-blind, placebo-controlled study was recently completed using 5\% acyclovir- $1 \%$ hydrocortisone cream. This study demonstrated that treatment with $5 \%$ acyclovir-1\% hydrocortisone cream resulted in a significantly higher percentage of nonulcerative recurrences (aborted lesions), reduced lesion loss-of-hardcrust and healing time, and decreased mean maximum and cumulative lesion area compared with both topical acyclovir alone and placebo. This was the first large-scale clinical study to demonstrate statistically significant improvement in recurrent herpes labialis using a corticosteroid.

$5 \%$ Acyclovir-1\% hydrocortisone cream Xerese (Xerclear) was approved for marketing in the United States in July 2009 for treatment of recurrent herpes labialis. It is indicated to reduce the likelihood of ulcerative cold sores and to shorten lesion healing time. It has also been approved for use in many other countries since 2009. Extensive reviews of this field and Xerese have recently been published by Harmenberg et al and Hull et al. ${ }^{45,46}$ This new method of treatment expands the spectrum of benefits derived by current antiviral treatments for herpes simplex labialis.

\section{Disclosure}

Dr Spruance was a consultant for Medivir. Dr Hull was an investigator for Medivir.

\section{References}

1. Spruance SL. The natural history of recurrent oral-facial herpes simplex virus infection. Semin Dermatol. 1992;11:200-206.

2. Embil J, Stephens R, Manuel F. Prevalence of recurrent herpes labialis and aphthous ulcers among young adults on six continents. Can Med Assoc J. 1975;113:627-630.

3. Ship I, Morris A, Durocher R, Burket L. Recurrent aphthous ulcerations and recurrent herpes labialis in a professional school student population. Oral Surgery. 1960;13:1191-1202.

4. Grout P, Barber VE. Cold sores - an epidemiological survey. J R Coll Gen Pract. 1976;26:428-434.
5. Young SK, Rowe NH, Buchanan RA. A clinical study for the control of facial mucocutaneous herpes virus infections. I. Characterization of natural history in a professional school population. Oral Surg Oral Med Oral Pathol. 1976;41:498-507.

6. Fleming DT, McQuillan GM, Johnson RE, et al. Herpes simplex virus type 2 in the United States, 1976 to 1994. N Engl J Med. 1997;337: 1105-1111.

7. Nahmias AJ, Lee FK, Beckman-Nahmias S. Sero-epidemiological and-sociological patterns of herpes simplex virus infection in the world. Scand J Infect Dis Suppl. 1990;69:19-36.

8. Xu F, Sternberg MR, Kottiri BJ, et al. Trends in herpes simplex virus type 1 and type 2 seroprevalence in the United States. JAMA. 2006;296: 964-973.

9. Villarreal EC. Current and potential therapies for the treatment of herpes-virus infections. Prog Drug Res. 2003;60:263-307.

10. Raborn GW, Grace MG. Recurrent herpes simplex labialis: selected therapeutic options. J Can Dent Assoc. 2003;69:498-503.

11. Richards DM, Carmine AA, Brogden RN, Heel RC, Speight TM, Avery GS. Acyclovir. A review of its pharmacodynamic properties and therapeutic efficacy. Drugs. 1983;26:378-438.

12. Jensen LA, Hoehns JD, Squires CL. Oral antivirals for the acute treatment of recurrent herpes labialis. Ann Pharmacother. 2004;38:705-709.

13. Spruance SL, Kriesel JD. Treatment of herpes simplex labialis. Herpes. 2002;9:64-69.

14. Habbema L, de Boulle K, Roders GA, Katz DH. n-Docosanol 10\% cream in the treatment of recurrent herpes labialis: a randomised, double-blind, placebo-controlled study. Acta Derm Venereol. 1996;76:479-481.

15. Spruance SL, Schnipper LE, Overall JC Jr, et al. Treatment of herpes simplex labialis with topical acyclovir in polyethylene glycol. J Infect Dis. 1982;146:85-90.

16. Spruance SL, Crumpacker CS, Schnipper LE, et al. Early, patientinitiated treatment of herpes labialis with topical 10\% acyclovir. Antimicrob Agents Chemother. 1984;25:553-555.

17. Raborn GW, McGaw WT, Grace M, Houle L. Herpes labialis treatment with acyclovir 5 per cent ointment. J Can Dent Assoc. 1989;55: 135-137.

18. Fiddian AP, Ivanyi L. Topical acyclovir in the management of recurrent herpes labialis. Br J Dermatol. 1983;109:321-326.

19. Whitley RJ, Levin M, Barton N, et al. Infections caused by herpes simplex virus in the immunocompromised host: natural history and topical acyclovir therapy. J Infect Dis. 1984;150:323-329.

20. Spruance SL, Nett R, Marbury T, Wolff R, Johnson J, Spaulding T. Acyclovir cream for treatment of herpes simplex labialis: results of two randomized, double-blind, vehicle-controlled, multicenter clinical trials. Antimicrob Agents Chemother. 2002;46:2238-2243.

21. Spruance SL, Rea TL, Thoming C, Tucker R, Saltzman R, Boon R. Penciclovir cream for the treatment of herpes simplex labialis. A randomized, multicenter, double-blind, placebo-controlled trial. Topical Penciclovir Collaborative Study Group. JAMA. 1997;277:1374-1379.

22. Raborn GW, Martel AY, Lassonde M, Lewis MA, Boon R, Spruance SL. Effective treatment of herpes simplex labialis with penciclovir cream: combined results of two trials. J Am Dent Assoc. 2002;133: 303-309.

23. Raborn GW, McGaw WT, Grace M, Tyrrell LD, Samuels SM. Oral acyclovir and herpes labialis: a randomized, double-blind, placebo-controlled study. J Am Dent Assoc. 1987;115:38-42.

24. Spruance SL, Stewart JC, Rowe NH, McKeough MB, Wenerstrom G, Freeman DJ. Treatment of recurrent herpes simplex labialis with oral acyclovir. J Infect Dis. 1990;161:185-190.

25. Spruance SL, Rowe NH, Raborn GW, Thibodeau EA, D'Ambrosio JA, Bernstein DI. Peroral famciclovir in the treatment of experimental ultraviolet radiation-induced herpes simplex labialis: a double-blind, dose-ranging, placebo-controlled, multicenter trial. J Infect Dis. 1999;179:303-310.

26. Spruance SL, Bodsworth N, Resnick H, et al. Single-dose, patientinitiated famciclovir: a randomized, double-blind, placebo-controlled trial for episodic treatment of herpes labialis. J Am Acad Dermatol. 2006;55:47-53. 
27. Hull C, Spruance S, Tyring S, Hamed K. Single-dose famciclovir for the treatment of herpes labialis. Curr Med Res Opin. 2006;22: 1699-1702.

28. Spruance SL, Jones TM, Blatter MM, et al. High-dose, short-duration, early valacyclovir therapy for episodic treatment of cold sores: results of two randomized, placebo-controlled, multicenter studies. Antimicrob Agents Chemother. 2003;47:1072-1080.

29. Spruance S. Herpes. Simplex labialis. In: Sacks SL, Straus SE, Whitley RJ, Griffiths PD, editors. Clinical Management of Herpes Viruses. Amsterdam: IOS Press; 1995:3-42.

30. Spruance S. Treatment of herpes simplex labialis. DeClerq E, editor. Clinical Use of Antiviral Drugs. Boston: Martinus Nijhoff; 1988:67-86.

31. Spruance SL, Evans TG, McKeough MB, et al. Th1/Th2-like immunity and resistance to herpes simplex labialis. Antiviral Res. 1995;28: 39-55.

32. Spruance SL, McKeough MB. Combination treatment with famciclovir and a topical corticosteroid gel versus famciclovir alone for experimental ultraviolet radiation-induced herpes simplex labialis: a pilot study. J Infect Dis. 2000;181:1906-1910.

33. Saez-Llorens X, McCracken GH Jr. Antimicrobial and antiinflammatory treatment of bacterial meningitis. Infect Dis Clin North Am. 1999;13:619-636, vii.

34. MacFadden D, Edelson J, Hyland R, Rodriguez C, Inouye T, Rebuck A. Corticosteroids as adjunctive therapy in treatment of Pneumocystis carinii pneumonia in patients with acquired immunodeficiency syndrome. Lancet. 1987;1:1477-1479.

35. Pneumonia TNIoH-UoCEPfCaATfP. Consensus statement on the use of corticosteroids as adjunctive therapy for pneumocystis pneumonia in the acquired immunodeficiency syndrome. $N$ Engl J Med. 1990;323:1500-1504.

36. Whitley RJ, Weiss H, Gnann JW Jr, et al. Acyclovir with and without prednisone for the treatment of herpes zoster. A randomized, placebocontrolled trial. The National Institute of Allergy and Infectious Diseases Collaborative Antiviral Study Group. Ann Intern Med. 1996; $125: 376-383$.
37. Guess S, Stone DU, Chodosh J. Evidence-based treatment of herpes simplex virus keratitis: a systematic review. Ocul Surf. 2007;5: 240-250.

38. Knickelbein JE, Hendricks RL, Charukamnoetkanok P. Management of herpes simplex virus stromal keratitis: an evidence-based review. Surv Ophthalmol. 2009;54:226-234.

39. Awan AR, Harmenberg J, Flink O, Field HJ. Combinations of antiviral and anti-inflammatory preparations for the topical treatment of herpes simplex virus assessed using a murine zosteriform infection model. Antivir Chem Chemother. 1998;9:19-24.

40. Awan AR, Harmenberg J, Kristofferson A, Field HJ. Herpes simplex virus zosteriform lesions with adoptive transfer of immune cells: a murine model which mimics human recurrent disease. Antiviral Res. 1998;38:43-53.

41. Evans TG, Bernstein DI, Raborn GW, Harmenberg J, Kowalski J, Spruance SL. Double-blind, randomized, placebo-controlled study of topical 5\% acyclovir-1\% hydrocortisone cream (ME-609) for treatment of UV radiation-induced herpes labialis. Antimicrob Agents Chemother. 2002;46:1870-1874.

42. Hull C, McKeough M, Sebastian K, Kriesel J, Spruance S. Valacyclovir and topical clobetasol gel for the episodic treatment of herpes labialis: a patient-initiated, double-blind, placebo-controlled pilot trial. J Eur Acad Dermatol Venereol. 2009;23:263-267.

43. Hull CM, Harmenberg J, Arlander E, et al. Early treatment of cold sores with topical ME-609 decreases the frequency of ulcerative lesions: a randomized, double-blind, placebo-controlled, patient-initiated clinical trial. J Am Acad Dermatol. 2010 Sep 17. [Epub ahead of print]

44. Hull CM, McKenna JK, Zone JJ. Topical corticosteroids and bullous pemphigoid. Arch Dermatol. 2003;139:225-226.

45. Harmenberg J, Oberg B, Spruance S. Prevention of ulcerative lesions by episodic treatment of recurrent herpes labialis: A literature review. Acta Derm Venereol. 2010;90:122-130.

46. Hull CM, Brunton $\mathrm{S}$. The role of topical $5 \%$ acyclovir and $1 \%$ hydrocortisone cream (Xerese) in the treatment of recurrent herpes simplex labialis. Postgrad Med. 2010;122:1-6.
Virus Adaptation and Treatment

\section{Publish your work in this journal}

Virus Adaptation and Treatment is an international, peer-reviewed open access journal focusing on the study of virology, viral adaptation and the development and use of antiviral drugs and vaccines to achieve improved outcomes in infection control and treatment. The journal welcomes original research, basic science, clinical \& epidemiological studies,

\section{Dovepress}

reviews \& evaluations, expert opinion and commentary, case reports and extended reports. The manuscript management system is completely online and includes a very quick and fair peer-review system, which is all easy to use. Visit http://www.dovepress.com/testimonials.php to read real quotes from published authors. 